\title{
Time-out from fixed-ratio reinforcement: A systematic replication
}

Donald M. Thompson UNIVERSITY OF VIRGINLA

\begin{abstract}
Abstraet
This study provided a systematic replication of the "FR-TO effect": the finding that escapes from a fixedratio $\mathrm{S}^{\mathrm{D}}$ increase as the work requirement is made more demanding. It made little difference whether the session was based on a constant number of reinforcements or on a constant period of time.
\end{abstract}

\section{Problem}

Under certain conditions, an organism will acquire and maintain a response which removes a stimulus associated with positive reinforcement. Specifically it has been demonstrated that rats and pigeons, working on fixed-ratio (FR) schedules, will occasionally respond on a second manipulandum to produce a "time-out" (TO) condition, during which extinction and its correlated stimulus $\left(S^{\Delta}\right)$ are in effect (Azrin, 1961; Appel, 1963; Thompson, 1964). It has also been found that frequency (Thompson, 1964) and duration (Azrin, 1961) of selfimposed TO are increasing monotonic functions of the FR requirement. This finding ("FR-TO effect'), taken together with the observation that TOs are typically restricted to the post-reinforcement pause, suggests that the TO response can be viewed as an escape from some aversive aspect of the FR schedule; for example, effort and/or delay of reinforcement.

The main purpose of the present investigation was to provide a systematic replication (Sidman, 1960) of the FR-TO effect. A procedure (fixed-duration TO) previously used with rats (Thompson, 1964) was employed with pigeons in order to establish interspecies generality. Also of interest was the comparison of two different bases for terminating the session: fixed time vs. fixed number of reinforcements. Zimmerman \& Ferster (1964) recently suggested that this variable may be critical in obtaining the FR-TO effect.

\section{Subjeets}

Two adult, male, White Carneaux pigeons ( $\mathrm{P}-1$ and $\mathrm{P}-2)$ served as subjects. Both had previously been used in an experiment involving different colored key-lights and variable-interval schedules of reinforcement. The birds were maintained at $80 \%$ of their free-feeding weights, and were run on alternate days. Water was available at all times.

\section{Apparatus}

A pigeon box of the type described in detail elsewhere (Ferster \& Skinner, 1957) was modified to contain two response keys: the FR key (blue), located above the food hopper on the front wall, and the TO key (white), at the same height situated on the side wall opposite the door. A white houselight was mounted on the back wall near the ceiling. The experimental chamber was enclosed in a ventilated, sound-attenuated picnic box, and was wired to automatic programming and recording equipment located in an adjacent room.

\section{Procedure}

Little preliminary training was necessary since the birds were not experimentally naive. After five sessions at FR 50, the TO key was illuminated and made functional. One peck on this key extinguished both key lights and simultaneously turned on the houselight. Exploratory research had indicated that under such conditions, key pecking is virtually eliminated. During the TO of 30 sec., responding on either key was recorded, but had no programmed consequence.

For both birds, the ratio requirement was progressively increased in steps of 50 from FR 50 to FR 300 (ascending sequence), after which FR 50 was reinstated in an attempt to establish recoverability. At each FR requirement, sessions were continued until TO performance showed no systematic day-to-day variation. For P-1, each session was terminated after $2 \mathrm{hr}$; for $\mathrm{P}-2$, each session was continued until 30 reinforcements had been received. Throughout the experiment, reinforcement consisted of 5-sec. access to mixed grain. A 'blackout" condition (all lights extinguished) was in effect before and after each session.

\section{Results and Discussion}

Figure 1 shows that number of TOs imposed during the final session at each FR requirement. As can be seen, the functions for both birds are monotonically increasing, and suggest the presence of an exponential relationship. This is consistent with the findings of Azrin (1961), Appel (1963), and Thompson (1964). Moreover it should be noted that the recovery of TO performance at FR 50 was virtually complete, thus replicating the Thompson (1964) study with rats.

In a series of exploratory manipulations with pigeons, Zimmerman \& Ferster (1964) consistently failed to find the FR-TO effect. Since their sessions were based on a constant number of reinforcements, in contrast to previous studies using fixed-duration sessions, they suggested that this may be a critical procedural difference. The present investigation, however, does not support this hypothesis, as shown by the remarkable similarity between the forms of the functions for the two birds (Fig. 1). In fact, more TOs were imposed by the constant-reinforcement bird (P-2), with the difference between $\mathrm{P}-2$ and $\mathrm{P}-1$ becoming greater as the ratio requirement increased. Although this may represent 


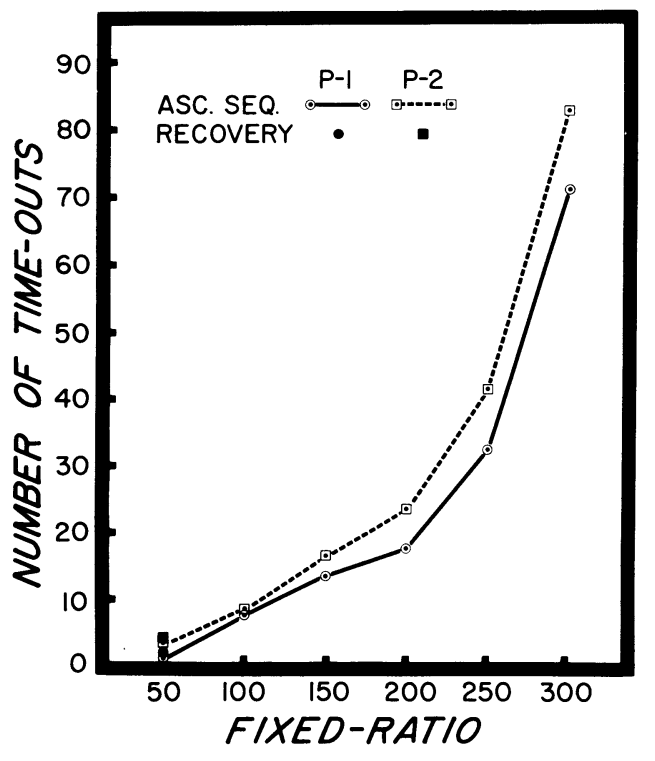

Fig. 1. Number of time-outs as a function of the fixed-ratio requirement for birds P-1 and P-2. Both the ascending sequence and recovery data points are based on the last session at each fixedratio value.

nothing more than "individual differences," it can be explained by the fact that session length for P-2 at FR 300 was at least double that of P-1, thus providing greater opportunity for TO responses to be made. There are, however, other procedural differences which might account for the Zimmerman-Ferster results, a likely candidate being the duration of TO. In the phase of their study most closely related to the present one ("minimum-duration" procedure), a 10-sec. TO was employed. This is in contrast to the fixed $30-\mathrm{sec}$. TO used both in the Thompson (1964) study and in the present investigation. Perhaps the effectiveness of TO as a reinforcer depends upon its duration.

Figure 2 shows the cumulative response curves of P-1 for the first half of the final session at each FR requirement. Applying the "interocular test" (Edwards et al., 1963) to these data, it is readily apparent that TOs increase as a function of FR magnitude. Especially note the recovery at FR 50 as compared to the preceding FR 300 data. It should also be noted that TOs typically occurred after reinforcement and before the next ratio burst, thus suggesting that the post-reinforcement pause is the most aversive point within the FR schedule (cf. Azrin, 1961; Appel, 1963; Thompson, 1964).

This experiment, as well as the others cited, have been concerned with e s c a pe procedures. It has been

\section{FIXED RATIO}

P-I

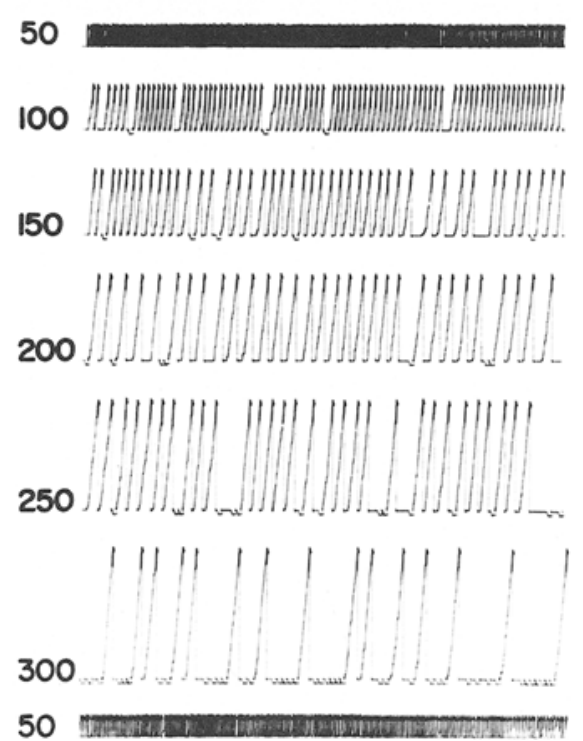

Fig. 2. Cumulative records of bird $\mathrm{P}-1$ for the first hour of the final session at each fixed-ratio requirement. The response pen reset after each reinforcement and was deflected below the baseline during the 30 -sec. time-outs.

argued, however (Zimmerman \& Ferster, 1964), that acceptance of a hypothesis which states that $\mathrm{TO}$ is reinforcing because it allows the organism to escape from some aversive condition within the FR schedule depends upon independent measurement of this aversiveness. One such demonstration is the finding that an avoidance response can be maintained when it prevents an increase in the ratio requirement (Findley, 1958). Still, in order to complete the picture, evidence is needed showing that a stimulus associated with an FR schedule can $\mathrm{p}$ un i $\mathrm{h}$ on-going behavior, with the degree of suppression being a function of FR magnitude. References

APPEL, J. B. Aversive aspects of a schedule of positive reinforcement. J. exp. Anal. Behav., 1963, 6, 423-428.

AZRIN, N. H. Time out from positive reinforcement. Science, 1961, $133,382-383$.

EDWARDS, W., LINDMAN, H., \& SAVAGE, L. J. Bayesian statistical inference for psychological research. Psychol. Rev., 1963, 70, 193-242.

FERSTER, C. B., \& SKINNER, B. F. Schedules of reinforcement. New York: Appleton-Century-Crofts, 1957.

FINDLEY, J. D. Preference and switching under concurrent scheduling. J. exp. Anal. Behav., 1958, 1, 123-144.

SIDMAN, M. Tactics of scientific research. New York: Basic Books, Inc., 1960.

THOMPSON, D. M. Escape from $\mathrm{S}^{\mathrm{D}}$ associated with fixed-ratio reinforcement. J. exp. Anal. Behav., 1964, 7, 1-8.

ZIMMERMAN, J., \& FERSTER, C. B. Some notes on time out from reinforcement. J. exp. Anal. Behav., 1964, 7, 13-19. 